\title{
Quantitative root ecology as element of soil fertility theory
}

\author{
M. van Noordwijk and P. de Willigen
}

Institute for Soil Fertility, P.O. Box 30003, 9750 RA Haren, Netherlands

\begin{abstract}
Quantified hypotheses on the relation between root density, mobility of the nutrient concerned and possibilities for actual uptake have to be developed and tested as building stones of 'soil fertility theory'. Depending on the mobility of the nutrient concerned and the buffering capacity of the soil-root system, emphasis should be placed on a comparison of nutrient supply and demand in time ('synchronization') or in space ('synlocalization'). A model approach is outlined.
\end{abstract}

\section{Introduction}

Through a largely empirical approach farmers and agricultural scientists in the past have developed effective techniques for manipulating the root's environment to increase crop yields, despite their limited understanding of root growth and function. A system of fertilizer recommendations was developed on the basis of large numbers of field trials, with only qualitative concepts of underlying processes. As the economic and environmental demands on agriculture shift from 'maximum production' to 'high efficiency at high production levels', a finer attuning of fertilization to actual crop requirements is necessary, which demands a better, quantitative understanding of underlying processes, including root growth and function. In a strict economic sense it is no problem if through empirically based fertilization techniques only $50 \%$ of nutrients applied as fertilizers are taken up by the crop. Present-day pressure on agriculture, however, requires maximization of nutrient use efficiency in agricultural systems, as nutrients not used by the crop generally lead to environmental problems (pollution of surface water, groundwater, soil or air) and fossil nutrient supplies and fossil energy used for making fertilizers are derived from limited resources. Recent development of soil analysis schemes to adjust $\mathrm{N}$ fertilization levels for potatoes to the amounts of mineral $\mathrm{N}$ in the soil may serve as an example: the method does not improve yields, but gives equal economical results to the farmer while saving, on average, $40 \mathrm{~kg} \mathrm{~N}$ per ha on the conventional advice of applying $245 \mathrm{~kg}$ ha regardless of soil $\mathrm{N}$ levels (Neeteson, 1985). Still, only about $60 \%$ of the $\mathrm{N}$ fertilizer applied is taken up by the potato crop. The fine-tuning of fertilization schemes which is now required probably cannot be accomplished unless we have better quantified theories about the balance between nutrient demand by the crop and nutrient supply from the soil. The uncertainties and variation inherent in the purely experimental approach hinder the refinement required. 
In developing a better understanding of this balance between supply and demand, concepts of root growth and function play a major role. Concepts of root growth and function have gradually changed over the past century from a 'morphological equilibrium', which can be summarized as 'the more roots the better shoot growth', to a 'functional equilibrium', distinguishing separate optima for root growth and root function (van Noordwijk \& de Willigen, in prep.). To obtain maximum crop production, relatively small root systems can be sufficient, provided the supply of water and nutrients is continuously high. Larger root systems may, however, increase nutrient use efficiency and hence reduce losses to the environment and environmental pollution.

\section{Nutrient use efficiency}

Efficiency of a system can be defined as the ratio of output to input. More specifically, often the output level is prescribed and the required input levels for obtaining such output are determined. When considering nutrient use efficiency we may deal with systems at three levels, with different inputs and outputs.

1. The soil/plant system. Efficiency on this level can be expressed in terms of an annual nutrient balance at crop level as 'fertilizer recovery' (nutrient uptake by the crop divided by amount of nutrients applied as fertilizer or manure).

2. The 'agro-ecosystem'. Aspects of crop rotation and/or mixed farming complicate the analysis, as components of the system may provide inputs to other components. Nutrient use efficiency should be considered on the level of a long-term nutrient balance at the farm gate, with sold products (and/or manure) as output and bought fertilizer and/or manure as input.

3. The 'human ecosystem' level. If both the sites of agricultural production and consumption are considered, nutrient use efficiency gets a further dimension. Recycling urban wastes reduces the need for new inputs in the form of fertilizer and thus increases nutrient use efficiency considered at this level, although chemical fertilizers may give a higher (partial) nutrient use efficiency at the crop level (level 1).

In the present discussion we will concentrate on level 1, as this is a building stone of considerations at higher levels of complexity. High root densities generally lead to more complete 'mining' of the soil. If the long-term nutrient balance of the soil (level 2) is neglected, this efficient mining may seem directly positive for increasing 'nutrient use efficiency'. High root densities may have a positive effect on nutrient use efficiency at level 2 in so far as they can reduce losses of nutrients to the environment. As the rate of a number of processes leading to losses to the environment depends on current concentrations in the soil (leaching, volatilization), the possibility of sufficient nutrient uptake by the crop at lower levels of current soil fertility may lead to higher nutrient use efficiency in the long run as well (Fig. 1).

To some extent the fertilizer recommendation schemes developed from statistical analysis of large numbers of field trials can be seen as 'regulatory systems'. Comparable to the general shape of the curve in Fig. 1 the recommended P fertilization decreases with indicators of soil P content (van der Paauw, 1973). At low levels 


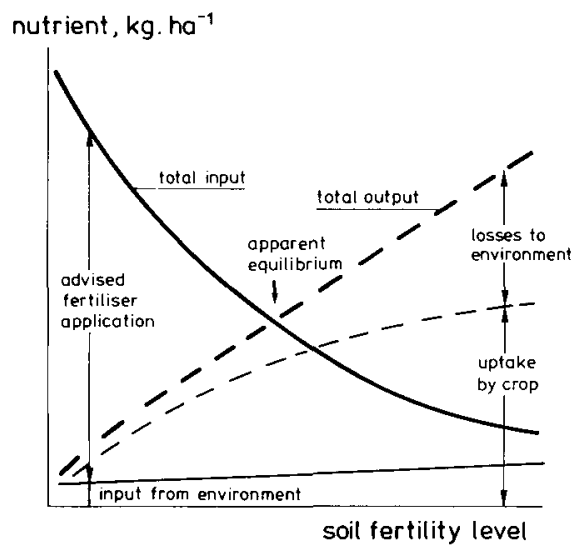

Fig. 1. Schematic representation of the elements of the nutrient balance in relation to current soil fertility levels; on the input side recommended fertilizer application generally decreases with soil fertility lev$\mathrm{el}$, while other inputs from the environment will be constant (input with rain, etc.) or increase (supply from previously 'unavailable' soil chemical constituents); on the output side crop uptake increases to a saturation level, losses to the environment may increase indefinitely).

of available soil $\mathrm{P}$ recommended $\mathrm{P}$ fertilization exceeds crop nutrient extraction and total soil $P$ levels will rise, which, depending on the buffering capacity of the soil, will also lead to a rise of available soil $P$ available to the plant in the long run. At high levels of soil $P$ the reverse is true and, if farmers follow the advice, soil $P$ levels (both total and 'available') will decrease. The scheme indicates that there is one specific soil fertility level at which Liebig's statement that fertilization should equal crop nutrient extraction is valid. Whether or not plant-available soil $P$ levels will remain constant at this point (i.e. whether or not it is a true equilibrium point), depends on the buffering behaviour of the soil, as determined by soil chemical factors. In Table I the position of this 'apparent equilibrium point', which plays a role in present discussions on limitations to fertilization for environmental reasons, is estimated from the current Dutch $\mathbf{P}$ fertilization advisory scheme (the estimates of crop uptake refer to the time that the scheme was made; present-day uptake reaches higher values). For the discussion of nutrient-use efficiency the position of this 'equilibrium' level and the possibility of avoiding losses to the environment at this level of soil fertility (at which maximum crop production is possible) are essential. For different crops the 'apparent equilibrium point', established from field experiments under 'typical' conditions for each crop, differs considerably. For a given crop the position of the equilibrium point can be modified, for example by soil compaction (Prummel, 1975). Differences might be related to crop uptake patterns, root densities reached by the crop, uptake potential per unit root length, influence of roots on $\mathrm{P}$ availability, and/or influence on $\mathrm{P}$ availability by soil moisture regime and soil structure typical for the various crops. Further analysis seems to be needed. 


\section{Soil fertility theory}

Fig. 2 shows how the relationship between fertilizer, manure or contaminant application and dry matter yield, as conventionally studied in field experiments (quadrant II), can be analysed in three other quadrants. Quadrant III describes the nutrient or contaminant balance for the soil, relating the amount of nutrient or contaminant in the 'potentially available' pool to the amount applied as input and to the amount lost to the environment (chemical 'speciation' and mobility are of major concern here for fertilizers and contaminants (cf. de Haan et al., 1986), soil microbiological interactions for organic inputs to the soil). Quadrant IV describes the nutrient uptake efficiency of the root system, relating actual uptake to potential availability (as affected by root density, soil moisture, soil structure, etc.; cf. Hamblin, 1985). Quadrant I relates nutrient uptake by the crop to dry matter production. If the three types of relationship in quadrants III, IV and I are known for a certain set of conditions (soil, crop, water balance, etc.), the relationship in quadrant II can be predicted. The domains of the quadrants can be named: I 'plant nutrition', II 'fertilization', III 'soil science' (including soil physics, biology and chemistry) and IV 'root ecology'. Of course, the quadrants cannot be studied strictly independent of each other: crop uptake influences the nutrient balance, crop requirements influence actual uptake levels, etc.

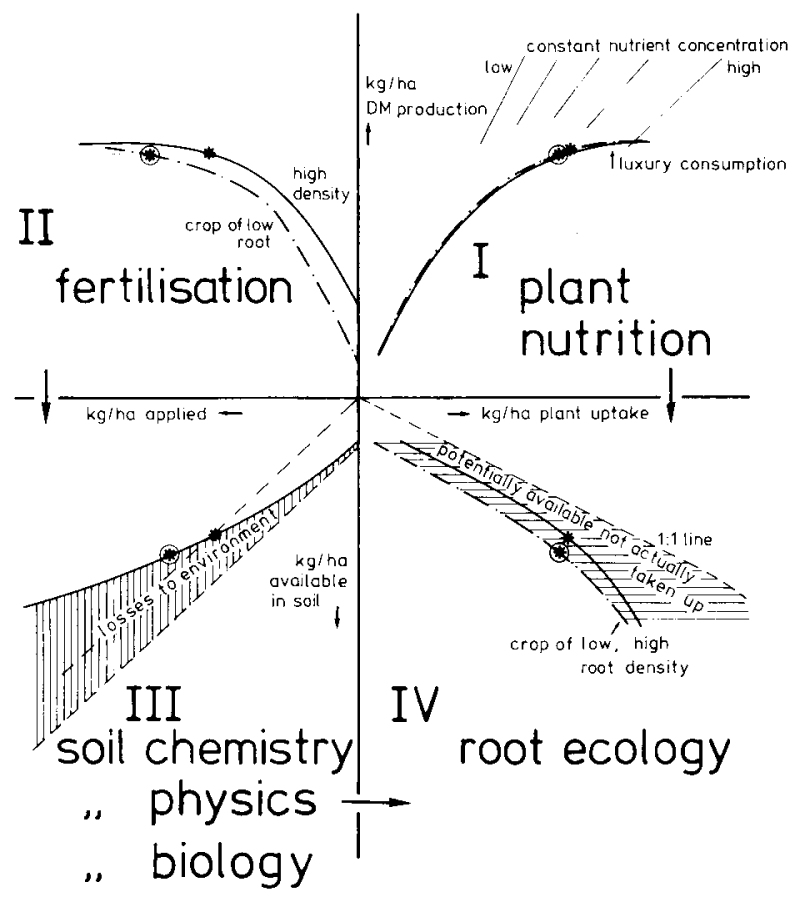

Fig. 2. Four-quadrant scheme for analysing soil fertility (see text for explanation). 


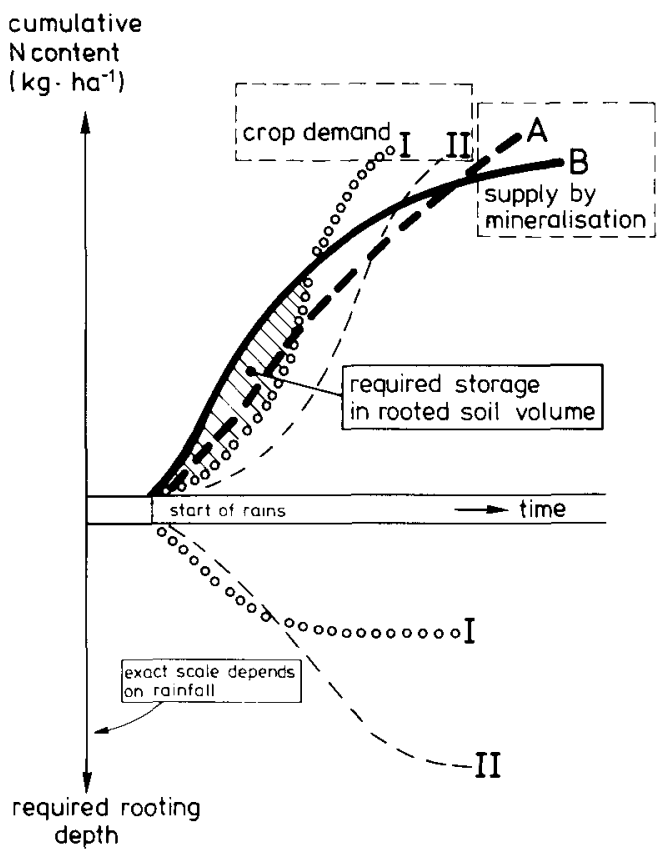

Fig. 3. Lack of synchronization between mineralization and nutrient demand by a crop and rooting depth required for recovery of leached nutrients (exact scale depends, for instance, on rainfall; a detailed version has been published by de Willigen, 1985).

Fig. 2 tentatively shows how a difference in root intensity of two crops can influence the possibilities for uptake in quadrant IV. If we may assume that the relation between nutrient uptake and dry matter production is the same for the two crops, the crop with the denser root branching may reach the same dry matter production at lower current soil fertility levels (quadrant IV), leading to lower input requirements and lower losses to the environment (quadrant III). More detailed discussions obviously depend on the nutrient concerned and the shape of the relationships in each of the quadrants.

The relations in quadrant III depend on the mobility and buffering of the nutrient concerned in the agricultural system under consideration. An extreme of high mobility and low buffering for all nutrients is formed by the situation in modern horticulture that uses nutrient solution in various substrates. Daily or hourly balances between nutrient supply and nutrient demand by the crop have to be considered in such systems, unless very low nutrient use efficiencies are accepted (van Noordwijk, 1983b). Similar situations in which synchronization of supply and demand are essential for the efficiency of the system occur in the humid tropics on soils of low chemical buffering for $\mathrm{N}$ and cations and continuous leaching throughout the growing season. Rooting depth is important under such conditions, as it determines the physical size of the buffering compartment (Fig. 3; de Willigen, 1985; Hairiah \& 
van Noordwijk, 1986). In temperate regions leaching during the growing season is more rare (except on light soils) and considerations of nutrient balances on the basis of a growing season become meaningful. In most soils the mobility of nutrients is higher for $\mathrm{N}$ (main buffering by soil (micro)organisms) than for $\mathrm{K}$, which in turn is higher than that for P (except in soils in which the chemical P-buffering capacity is virtually filled up (Raats et al., 1982), as in some glasshouse soils in the Netherlands; R. G. Gerritse, pers. comm.). Dry soil conditions reduce mobility of all nutrients, and even $\mathrm{N}$ supply to the roots in topsoil may become problematic (Garwood \& Williams, 1967). With decreasing mobility and increasing buffering, the main aspect of concern gradually shifts from time ('synchronization' of nutrient supply and demand, in relation to the growth stages of the crop), to details of spatial arrangement ('synlocalization' of roots and nutrients, for instance as influenced by soil structure).

\section{Quantitative root ecology}

To specify the relations in quadrant IV, root density in the nutrient-containing zones of the soil (i.e. plough layer for most immobile nutrients, the whole rooted part of the profile for other nutrients) is a prime factor. Fig. 4 shows results of a pot experiment by F. van der Paauw in which both root density (root length per unit volume of soil) and nutrient demand per unit volume of soil were varied by using various pot sizes. $P$ uptake from soils of different $P$ status agree fairly well for potato and mustard when they are related to actual root length density. Mustard roots are slightly more effective in $\mathbf{P}$ uptake per unit root length, which might be connected with acidification of the rhizosphere (Clarkson, 1985). The general shape of the relationship between $P$ uptake and root length density agrees with a theory developed for regularly distributed, parallel root systems (de Willigen \& van Noordwijk, 1978; van Noordwijk \& de Willigen 1979; de Willigen, 1981).

Various factors in the root environment may modify the relationship between root density in the soil and nutrient uptake. Interactions with moisture are among the most important factors (Garwood \& Williams, 1967), as nutrient diffusion in the soil is strongly influenced by soil moisture content and water is the carrier of soil nutrients in soil solution, dictating leaching and mass-flow towards the root. Other complications arise from irregular distribution of roots in the soil (and/or irregular distribution of nutrients in soil), from partial contact between roots and soil, the influence of root hairs on this contact, interactions with mycorrhizal partners and other rhizosphere symbionts and from local influence of roots on the mobility of nutrients (Clarkson, 1985). The time course of plant demand for nutrients and possibilities for uptake by root growth, root survival and root decay are especially relevant for 'synchronization' studies.

In developing a theory for these more complex situations, we take the following steps:

a) total daily uptake requirement of the crop is divided by the number of roots present to obtain required uptake rates per unit root;

b) the soil-root system is characterized by one or more 'typical' roots, which deplete 


\section{VP 551-1962}

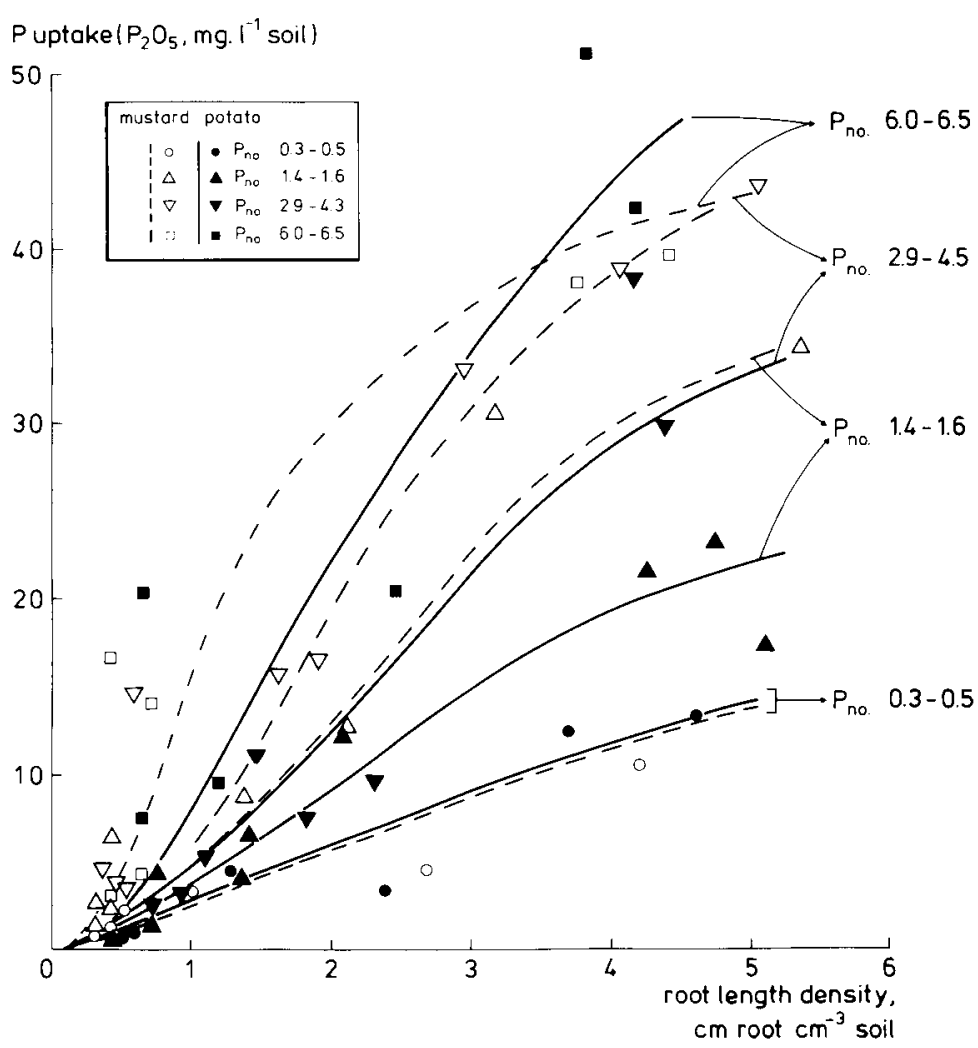

Fig. 4. P uptake by mustard and potato in a pot experiment in which root length density in the soil and nutrient demand per unit volume of soil were varied by changing pot sizes; 8 soils were used with different $P$ availability, as measured in a water extract ('P number', related to the later 'P water' method); (unpublished data of $F$. van der Paauw, root length data based on photographs of individual roots).

a certain amount of soil;

c) soil resources are supposed to be used at the required rate, until the root environment is depleted (this depletion is counteracted by transport towards the root) to a 'limiting' concentration at the root surface. At this 'limiting' concentration the physiological abilities of the root allow for a just sufficiently high uptake rate;

d) when the limiting concentration is reached a certain amount of potentially available resources (water or nutrients) still remains in the soil. This amount can be found by integrating the remaining concentration profile over the relevant area.

As main model result we use the period of unconstrained uptake (days), which can be compared with potential crop duration. Starting from a geometrically simple situation, we can investigate step by step the relative importance of more complex, hopefully more realistic assumptions. So far the work has been concentrated on $\mathrm{P}$ 
Table 1. Phosphate levels in the soil for which, for different crops, the present advisory scheme indicates that fertilizer application should equal nutrient uptake by the crop.

\begin{tabular}{llll}
\hline Crop uptake & $\begin{array}{l}\text { Estimated phosphorus } \\
\left(\mathrm{kg} \mathrm{ha}^{-1}\right)\end{array}$ & \multicolumn{2}{l}{$\begin{array}{l}\text { Pw number }\left(\mathrm{P}_{2} \mathrm{O}_{5}, \mathrm{mg} \mathrm{l}^{-1} \text { soil) at }\right. \\
\text { which fertilization equals uptake }\end{array}$} \\
\cline { 3 - 4 } & & $\begin{array}{l}\text { diluvial sands } \\
\text { basin clay }\end{array}$ & \multicolumn{1}{l}{$\begin{array}{l}\text { alluvial sands } \\
\text { and clay }\end{array}$} \\
Potato & 55 & 55 & 55 \\
Peas, beans & 40 & 50 & 35 \\
Maize & 80 & 45 & 45 \\
Barley & 45 & 45 & 30 \\
Sugar-beet & 100 & 30 & 25 \\
Wheat, rye, oats & 45 & 30 & 20 \\
\hline
\end{tabular}

and water (van Noordwijk, 1983a) for regularly distributed roots and on the consequences of partial root-soil contact for oxygen and nutrient uptake by roots (de Willigen \& van Noordwijk, 1984; de Willigen, 1984).

For phosphate it seems possible to understand required $P$ levels in the soil for adequate uptake by various crops (empirically established as in Table 1) on the basis of their Root Area Index. In the near future we hope to provide a theoretical framework for an understanding of the extent to which reduced nutrient availability in coarsely aggregated or compacted soils can be compensated for by additional fertilization (cf. Prummel, 1975). Basic knowledge of quadrants III, IV and I of Fig. 2 seems to be indispensable for a quick adjustment of fertilizer advisory schemes to changing conditions and for obtaining a higher nutrient use efficiency.

\section{Acknowledgements}

Thanks are due to Ir C. M. J. Sluijsmans and Dr Ir K. Dilz for constructive criticism during the preparation of the manuscript.

\section{References}

Clarkson, D. T., 1985. Factors affecting mineral nutrient acquisition by plants. Annual Review of Plant Physiology 36: 77-115.

Garwood, E. A. \& T. E. Williams, 1967. Growth, water use and nutrient uptake from the subsoil by grass swards. Journal of Agricultural Science 69: 125-130.

Haan, F. A. M. de, M. G. Keizer, Th. M. Lexmond, W. H. van Riemsdijk \& E. E. A. T. M. van der Zee, 1986. Some recent developments and approaches in soil protection research. Netherlands Journal of Agricultural Science 34: 361-370.

Hamblin, A. P., 1985. The influence of soil structure on water movement, crop root growth and water uptake. Advances in Agronomy 38: 95-158.

Hairiah, K. \& M. van Noordwijk, 1986. Root studies on a tropical ultisol in relation to nitrogen management. Rapport 7-86, Instituut voor Bodemvruchtbaarheid, Haren, Netherlands (in press).

Neeteson, J. J., 1985. Effectiveness of the assessment of nitrogen fertilizer requirement for potatoes on the basis of soil mineral nitrogen. In: J. J. Neeteson \& K. Dilz (Eds.), Assessment of nitrogen fertilizer requirement, p. 15-24. Instituut voor Bodemvruchtbaarheid, Haren, Netherlands. 
Noordwijk, M. van, 1983a. Functional interpretation of root densities in the field for nutrient and water uptake. In: Wurzelökologie und ihre Nutzanwendung, p. 207-226. Int. Symposium Gumpenstein (1982). Bundesanstalt Gumpenstein, Irdning.

Noordwijk, M. van, 1983b. Meststofgebruik in de substraatteelt: benutting of verspilling? Groenten en Fruit 39.23: 42-45.

Noordwijk, M. van \& P. de Willigen, 1979. Calculation of the root density required for growth in soils of different P-status. In: J. L. Harley \& R. Scott Russell (Eds.), The soil-root interface, p. 381-390. Academic Press, London.

Paauw, F. van der, 1973. Adjusting fertiliser rates to soil fertility level on the basis of soil testing. Pontificiae Academiae Scientiarum Scripta Varia No 38: 427-466.

Prummel, J., 1975. Effect of soil structure on phosphate nutrition of crop plants. Netherlands Journal of Agricultural Science 23: 62-68.

Raats, P. A. C., P. de Willigen \& R. G. Gerritse, 1982. Transport and fixation of phosphate in acid, homogeneous soils. I. Physicomathematical model. Agricultural and Environment 7: 149-160.

Willigen, P. de, 1981. Mathematical analysis of diffusion and mass-flow of solutes to a root assuming constant uptake. Rapport 6-81, Instituut voor Bodemvruchtbaarheid, Haren, Netherlands, $56 \mathrm{pp}$.

Willigen, P. de, 1984. Some theoretical aspects of the influence of soil-root contact on uptake and transport of nutrients and water. In: J. Bouma \& P. A. C. Raats (Eds.), Proceedings of the ISSS symposium on water and solute movement in heavy clay soils, pp. 268-275. ILRI, Wageningen.

Willigen, P. de, 1985. Modelling of transport, transformation and uptake of nitrogen in an Ultisol for high rainfall conditions. In: B. T. Kang \& J. van der Heide (Eds.), Nitrogen management in farming systems in humid and subhumid tropics. p. 73-86. Instituut voor Bodemvruchtbaarheid, Haren, and International Institute of Tropical Agriculture, Ibadan.

Willigen, P. de \& M. van Noordwijk, 1978. Berekeningen over fosfaatopname door een gewas in afhankelijkheid van bewortelingsdichtheid en fosfaatrijkdom van de grond. Rapport 19-78, Instituut voor Bodemvruchtbaarheid, Haren, Netherlands, $63 \mathrm{pp}$.

Willigen, P. de \& M. van Noordwijk, 1984. Mathematical models on diffusion of oxygen to and within plant roots, with special emphasis on effects of soil-root contact. I. Derivation of the models. Plant and Soil 77: 215-231. II. Applications. Plant and Soil 77: 233-241.. 